Agriculture 2012, 2, 339-358; doi:10.3390/agriculture2040339

OPEN ACCESS

agriculture

ISSN 2077-0472

www.mdpi.com/journal/agriculture

Article

\title{
The Agricultural Ethics of Biofuels: The Food vs. Fuel Debate
}

\section{Paul B. Thompson ${ }^{1,2,3}$}

1 Department of Philosophy, Michigan State University, East Lansing, MI 48824-1032, USA;

E-Mail: thomp649@msu.edu; Tel.:+1-571-432-0316; Fax: +1-517-353-8994

2 Department of Agricultural, Food and Resource Economics, Michigan State University, East Lansing, MI 48824-1032, USA

3 Department of Community, Agriculture, Recreation and Resource Studies, Michigan State University, East Lansing, MI 48824-1032, USA

Received: 18 September 2012; in revised form: 25 October 2012 / Accepted: 26 October 2012 / Published: 6 November 2012

\begin{abstract}
Plant-based transportation fuels were the focus of extended criticism in the press, especially during 2008 when a portion of the blame for a spike in global food prices was associated with growth of the United States' corn ethanol industry. The critique is based on an unsophisticated portrayal of the ethical issues at stake in the food security implications of biofuel. Three ethical critiques can be leveled at the food $v s$. fuel debate. First, although market drivers of biofuels indeed skew consumption of agricultural grains, this is not a problem that is unique to biofuels. Second, the critique does not reflect an adequate understanding of the way that rising food prices and changes in agricultural technology affect the food security of the poorest people. Third, although rising food prices could be beneficial to poor farm producers among the world's poor, it is unlikely that benefits will materialize in the absence of concerted programs to deliberately select biofuel development strategies that are targeted to strengthen food security for poor and small-holding producers. An adequate agricultural ethics for biofuels will require commitment by both private and public sector biofuel developers to ensure that potentially positive attributes of biofuel development are realized.
\end{abstract}

Keywords: hunger; food security; food prices; moral responsibility; transportation fuels 


\section{The Agricultural Ethics of Biofuels: The Food vs. Fuel Debate}

Hunger is morally compelling. If people believe that liquid transportation fuels derived from plant-based feedstocks will take food out of the mouths of hungry people, there is an ethically powerful argument against the entire package of technologies dedicated to improving the biological efficiency of converting plant matter into combustible fuels, as well as to research on agricultural and energy policies intended to increase utilization of biofuels. There are replies that can be made to the suggestion that food and fuel uses of agricultural crops are locked into a zero sum competition, and this paper will argue that the food $v s$. fuel trade-off is, in fact, extremely misleading with respect to the ethics of biofuel development. However, this does not exonerate the developers and promoters of various strategies for increasing global use of biofuel. Indeed, a more adequate interpretation of the ethical tensions between global food security and the growth of the biofuel production require the acknowledgement of responsibilities that are, at present, only dimly appreciated within the technical and business communities.

The term "biofuels" is used broadly in this paper. It includes technologies currently utilized for the production of ethanol from plant feedstocks such as maize or sugarcane and biodiesel from palm and other oil-rich plants. The term also indicates a much larger class of technologies that are currently the focus of extensive research and development (R\&D). These would include alternative crops for ethanol and biodiesel production, such as miscanthus or jatropha, as well as more efficient utilization of crop residues or multi-use strategies that would combine extraction of starch for fuel production with use of remaining nutrients (distillers' grain) for animal feeding. There are also very ambitious R\&D efforts to make woody biomass available for conversion to liquid fuel. The paper is focused on a public debate in which "biofuel" was implicitly understood to mean liquid transportation fuels that could substitute for petroleum-based fuels. For many non-specialists, the development of new sources for biofuel was also understood as a "technological fix" that would permit continued use of low fuel-efficiency automobiles such as the sport-utility vehicle (SUV). The liquid-fuels orientation to biofuels continues in the following ethical analysis, though some of the ethical arguments might well apply to other ways in which plant-based energy sources could be developed in the future [1].

The word "ethics" can be a source of confusion in scientific contexts. When used as plural noun, the word refers to codes or norms for human conduct. An individual, group or profession's ethics are indicated by these norms and to "have ethics" is to act in accordance with these codes. In this connection, institutional review boards for research involving human or animal subjects are sometimes referred to as "ethics committees". However, the word "ethics" has also been used as a singular noun to designate the discussion, debate and review of human conduct, especially when the criteria for right action are not readily identified on the basis of existing codes and norms. It is in this sense that ethics is as an important subfield in the discipline of philosophy. Although philosophers' analyses are intended to have eventual bearing on human conduct, they operate at one step removed from moralizing pronouncements that are intended to tell others what they should do. It is in this latter sense that this paper is an exercise in the agricultural ethics of biofuels. While philosophical ethics does not necessarily shy away from prescriptive statements that say what people should be doing, the point of a philosophical analysis is to illustrate and analyze the background assumptions and context in which the prescription is grounded. 
The paper is organized as follows: a brief overview of the food $v s$. fuel debate as it unfolded between 2007 and 2009 is succeeded by a discussion of responses to the debate as it moved from the popular news media into the journals and grey literature of technical and policy analysts. Although ethical claims are prominent in the food $v s$. fuel debate, very little of technical or policy literature attempts to address the issue of food security from an explicitly ethical perspective. Indeed, many contributions to the food $v s$. fuel debate appear to assume that a largely discredited "food availability" paradigm adequately articulates the problem of global hunger. Given the assumption that total global supply of food commodities is the primary driver for food security it is reasonable to presume that finding ways to limit biofuel production's impact on the available food supply is an ethically responsible answer to the food vs. fuel trade-off. But the answer overlooks a series of conceptual and technical problems which are discussed in a three stage analysis that concludes the paper.

First, it must be noticed that tensions between food and fuel uses for agricultural crops are in fact simply a special case within a more comprehensive and systematic disregard for the interests of the poor. Responses to the food $v s$. fuel debate that substitute biomass from non-food agricultural sources fail to address the underlying ethical question of resource allocation. Second, food insecurity is currently most endemic among poor people who are themselves food producers. Protecting the global supply of food commodities is thus often of negligible benefit to the food insecure. Increasing supplies can in fact be harmful to them. Thus finally, biofuels might be developed in a manner that is beneficial to many people living in extreme poverty, but doing so will require a far more detailed and place-specific understanding of food needs than can be derived from global statistics on food availability. Developers of biofuels thus must accept the burden of acquiring detailed understanding how implementation of the technology will affect food insecure people. Only then can they avoid the charge of moral insensitivity and irresponsibility.

\section{The Food vs. Fuel Debate: The Early Years}

The most general rationale for pursuing new technologies is that (a) someone (often the developer) will derive benefit from doing so, and (b) that no one else's interests will be thwarted in a morally significant way. There is the germ of an ethical argument even here, for if no third party is harmed, who can deny that projects of self-betterment deserve endorsement in ethical terms? Of course, specifying the meaning of benefit, on the one hand, or the conditions for a morally significant harm, on the other, is a large project that often provokes significant philosophical and political disagreements. "Technological ethics" can be understood as the activity of give and take argumentation that occurs in developing and contesting a rationale for technological projects, the body of literature that this activity generates, and also as the scholarly analysis of that argumentation. Furthermore, the social and historical context in which arguments are proffered or rejected is often crucial to their persuasiveness.

It is thus useful to understand how the idea of a food $v s$. fuel tension arose and came to be seen as a crucial theme in the technological ethics of biofuels. Writing before much of the food vs. fuel debate broke, I underplayed the significance of food security, although I also cautioned that "one should not dismiss the possibility that hungry people will be forced into a bidding war for grain with American SUVs," [2]. Within two years, the belief that conversion of plant matter into fuel was incompatible with meeting global food needs had become firmly established in the public mind. While development 
of biofuel had been a signature theme in then President George Bush's 2006 State of the Union Address, opinion polls taken in 2010 showed that the combination of environmental concerns and the potential for conflict between food and fuel uses of agricultural crops had softened public support significantly [3].

Opinion pieces that raised the specter of a clash between increased utilization of plant bio-mass for liquid fuel production began to surface as early as 2004 when George Monbiot, a columnist for the Manchester Guardian broached the topic in an editorial entitled "Feeding Cars, Not People," [4]. Such brief essays are important for understanding the ethics of biofuels precisely because they are explicit in their use of advocacy and their appeal to moral norms. While the argument in these opinion pieces appeals to factual claims and to a basis in economic theory, the primary point of such essays is to express an ethical judgment: Biofuels are immoral because they sacrifice the vital interests of the poor to favor the convenience of a much better-off middle class. Monbiot's articles thus differ from peer-reviewed articles by engineers, economists or biofuels scientists precisely because of the emphasis that they place on making moral claims.

Monbiot has continued to be one of the most visible public critics of biofuels as well as the most frequent promulgators of the food $v s$. fuel conflict [5,6]. He was joined by other critics between 2006 and 2008 including the respected ecologically oriented critic of industrial agriculture Lester Brown [7-10]. However, a series of articles in the prestigious opinion journal Foreign Affairs may have done the most to fix the idea of a food vs. fuel tension. C. Ford Runge and Benjamin Senaur sketched the basic argument for linking biofuels to a rise in global food princes in 2007 [11]. This was followed with a rebuttal from former U.S. Senator Tom Daschle and a reply by Runge and Senaur that offered further elaboration of the original argument, now backed with supporting data and economic analysis [12]. These opinion pieces were accompanied by a significant amount of coverage in the mainstream press during 2007. In January, The New York Times ran an article discussing a report from the Earth Policy Institute which projected that ethanol plants in operation, under construction or in planning could consume as much as $50 \%$ of the United States corn crop [13]. More Times coverage in 2008 focused on diversion of oils to biodiesel. This report linked biodiesel programs to food shortages and rising food costs for poor people in India and Malaysia [14]. Food vs. fuel tensions were also highlighted in several Times editorials in 2007 [15,16], including one that synopsized the Runge and Senauer piece in Foreign Affairs [17].

The emergence of a long predicted general rise in the price of major food commodities was the larger context for these articles and editorials identifying a link between ethanol and oil-based biodiesel and an uptick in global hunger. Much like any trend that encompasses a large number of otherwise independent events, worldwide increases in the price of basic food commodities occur in fits and starts, often associated with relatively short-term impacts on global food supply such as a major drought or pestilence in a single region. The general real price trends for agricultural commodities were downward for most of the 20th century, yet economists such as Brown had been predicting that this would be reversed at some point owing to the combination of declining quality of environmental resources, total population growth and the accompanying growth in per capita food consumption that is associated with economic development [18]. Whatever the underlying causality, it is clear that global price increases began to be obvious to everyone in 2007, and that they have continued with only occasional respite (typical of fits and starts) ever since. As many of the news reports listed above 
indicate, these price increases are often accompanied by protest and violence in the cities of the developing world.

The basic economic premises of the food $v s$. fuel argument have had and continue to have a significant amount of support from the academic literature. The idea that every buyer of a given commodity contributes to the overall demand for the commodity is a fundamental assumption of price theory. If the market for plant-based transportation fuels is expanding, it is axiomatic that this will be reflected in the shape of the demand curve for the crops being utilized for biofuels. However, the nature of this effect depends on factors such as the source of demand for all competing uses of the crop in question. In the case of maize used for ethanol production, for example, this would include direct human food consumption (including conversion to high fructose sweeteners), use for animal feeds and use for other industrial applications. The availability of substitutes for each use also affects demand, so calculation of biofuel's actual impact on commodity prices is quite complex. It is particularly important to notice that upward price trends in one food commodity can indirectly cause an increase in demand (and corresponding upward price tendencies) in others. Thus although there are competing economic analyses, there is little doubt that maize-based ethanol production is associated with upward effects on the price of global food commodities [19-21].

An economic analysis is not an ethical argument, however. To say that hunger is a moral problem implies that there is something regrettable about the circumstances of hungry people, and that someone should do something about it. Simply spelling out the sense in which hunger is a moral evil and then identifying who should take action (much less what actions should be take) would take the present discussion far afield, (however, see [22-24]). The perspective that drives the food vs. fuel debate is not deeply informed by moral theory, in any case. Hunger is simply presumed to be a moral evil that is familiar and understandable by anyone. The moral position argued in the food vs. fuel debate uses this basic moral assumption to build on the economic analysis. The economic analysis of food prices is then represented as a rationale for seeing growth in the market for biofuels as a cause of hunger. A key ethical judgment lies buried in the inference that since growth in the market for biofuels causes higher prices, such growth is also ethically a bad thing. Finally, the moral position holds that those who advocate growth in the use of biofuels are advocating a moral evil, and those scientists and entrepreneurs engaged in the development of biofuels are engaged in unethical projects. As I will argue below, this intuitively plausible argument is both vague and ambiguous in ethically important ways.

Nevertheless, the reality of increasing prices and the intuitive plausibility of a food $v s$. fuel explanation created a context in which an ethics-based critique of biofuels was able to take hold of the public imagination. It is important to note that there other dynamics provided additional impetus to this negative moral judgment. First, as I argued in 2008 Bush's linking of biofuels to the theme of energy independence and a strong anti-terrorist campaign grated on those who had become impatient with his nationalist political stance, and this impatience was felt both within and outside the United States [2]. In addition, economists such as Runge and Senaur were clearly irritated by the Bush Administration's utilization of what they took to be irrational and unjustified subsidies for the development of ethanol production [11] (see also [25]). They may have thus been especially eager to find rationales that would counter the direction of policy mandates that they took to be driving the growth of ethanol-based biofuels up to 2008 . 
It is also important to recognize that the food $v$. fuel debate was not isolated from environmental and political debates surrounding biofuels. A series of influential scientific papers on the life-cycle effects of maize-based ethanol production did substantial damage to the environmental reputation of biofuels between 2006 and 2008 [26-28]. What is more, there is a strong tendency for arguments that might apply to one plant-based source (such as maize or sugarcane) to be generalized to all forms of plant-based liquid transportation fuels, including cellulosic ethanol [29]. It would be difficult to disaggregate the impact that these critical perspectives on biofuels may have had when evaluating the impact and persuasiveness of the food $v s$. fuel criticisms. The analysis being offered here should not be interpreted as implying that there is strong empirical evidence for the thesis that moral claims linking biofuels to hunger play a singular role in influencing public opinion, in any case. My claim is simply that advancing these critiques in newspapers and opinion journals reinforces the peculiarly moral significance of the link between biofuels and global hunger, while simultaneously establishing a set of premises that constrain the range of contested issues. The important effect is the creation and delimitation of a rhetorical space in which the future of biofuels is debated. This effect can be observed in both popular and scholarly texts, and the sources cited here are put forward as evidence. It may be reasonable to assume that the assumptions shared by arguments appearing in the press are also shared by the public at large, but this paper makes no claims about the validity of such an assumption.

\section{The Ethics of Biofuels since 2007}

In one sense, the tenor of the debate over the ethics of biofuels has changed little since the flurry of opinion articles in 2007 and 2008. As of July 2012, the Wikipedia article under the title "Food vs. Fuel" contains extensive discussion of the debate as it unfolded during the food crisis of 2007 and 2008 along with updated citations suggesting that little has changed [30]. Two developments, however, are notable. One is the attempt to dissociate the use of non-food crops from the negative ethical implications of the food vs. fuel debate. The other is a major study on the ethical implications of existing ethanol production technologies conducted by the Nuffield Council in the United Kingdom. This latter effort is also tied to the emergence of consortia dedicated to mitigating adverse impacts of biofuel production through alliances such as Roundtable on Sustainable Biofuels [1]. Each of these efforts warrants a brief discussion before proceeding to a more substantive ethical analysis of the food vs. fuel debate.

It is not as if advocates for biofuels stood by and allowed critics such as Lester Brown or George Monbiot free reign. Countervailing opinions have been published, often simply dismissing the empirical claim of a causal link between plant-based liquid transportation fuels and the up-tick in global food prices [31]. Others simply assert that more income for farmers should be regarded as a good thing [32]. More sophisticated versions of such counter-opinion note the complexity of ascribing economic causality to any single source of economic demand, or point out that there are any number of drivers for price change (such as increasing meat consumption) that could also be assigned causal responsibility for upward prices [33]. However, the most pervasive (and perhaps persuasive) strategy has been to emphasize fuels that could be produced from non-food sources. One of the most important articles making this argument was published in Science in 2009. The article entitled "Beneficial Biofuels-The Food, Energy, and Environment Trilemma" was authored by individuals who had 
contributed scientific analyses on the environmentally detrimental impacts of biofuels, especially corn ethanol. It argued that future biofuels would need to address energy needs, but that doing so poses both environmental and food security challenges [34].

The primary strategies suggested for countering the "food, energy and environment trilemma" revolve around non-food plants as feedstocks for fuels. The article recognizes that there are several possible ways in which non-food plant sources could contribute to global energy needs. First, the article recommends the cultivation of non-food crops that might be used for ethanol production, including miscanthus and switchgrass. However, the authors go on to argue that the next generation of biofuels will utilize a wider variety of woody plants. One approach will be to modify the plants so that they can be more easily converted into ethanol or other fuels. An alternative approach will be to improve technology for breaking down the cell wall so that plant sugars are available for conversion into combustible liquid fuels. Finally, direct algal or microbial methods of fuel production utilizing organisms that have been genetically modified may represent a final step in removing edible plant sources from the pool of plant feedstocks being utilized for biofuel production [34]. In short, the paper argues that the solution to a food $v s$. fuel trade-off lies in utilizing feedstocks for fuel production that do not draw from the supply of food commodities. Although the argument does not address ethical concerns directly, it does suggest that the empirical claims behind the food vs. fuel critique can be averted by avoiding food crops. Other essays in a more popular vein make this claim explicitly [35].

The Nuffield Council's 2011 report on biofuels also encourages the use of non-food crops, but in light of the study group's decision to limit their focus to currently feasible and in-use technology, they do not give significant weight to crops (such as miscanthus) that lack a current commercial agronomic production regime, much less to cellulosic biofuels that presuppose significant technological breakthroughs. The report includes a lengthy description of several case studies of biofuels development from which its ethical conclusions are drawn. The study team emphasizes two rather general ethical themes. First, they argue at length for the importance of including an ethical assessment within any technical program to implement a biofuel production technology. Here the key point is simply that advocacy for biofuels should become self-conscious about the ethical implications of the rhetoric used to advocate for biofuel, and that this should include procedures for articulating, reviewing and critiquing those rationales in which the public can participate. They advocate the use of consensus processes and third-party certification schemes as a way to both implement a process of ethical reflection, and to monitor the success of biofuels programs in meeting ethically mandated goals [36,37]. A similar process of ethical reflection has also been recommended by other authors on the ethics of biofuels, often with a general discussion of how ethical deliberations can be conducted and how they can be organized with a broad cross-cultural appeal $[38,39]$.

The second main ethical contribution of the Nuffield Council report is a list of guiding principles for the development and implementation of biofuels. As summarized by two members of the study team, these principles are:

1. Biofuels development should not be at the expense of people's essential rights.

2. Biofuels should be environmentally sustainable.

3. Biofuels should contribute to net reduction of total GHG emissions and not exacerbate climate change. 
4. Biofuels should recognize the rights of people to just reward.

5. Cost and benefits of biofuels should be distributed in an equitable way [40].

The Nuffield principles do not make specific reference to the food vs. fuel debate. In some respects, the overall report downplays the importance of competition between food and fuel uses for agricultural production, though upward pressure on global commodity prices is discussed in connection with the Council's discussion of U.S. corn ethanol as one of its case studies. The overall tone of the report is to suggest that ethically acceptable biofuel implementation strategies are possible if compliance with the five principles is born in mind. Aside from endorsing the suggestion that non-food plant feedstocks be emphasized for biofuel production, the report does not provide any discussion of how compliance with the five principles would address criticisms arising from the food $v s$. fuel debate. It is therefore useful to make note of how the Nuffield Council principles can be brought to bear on questions of food security.

Although the Nuffield Council stresses the point that all five of these principles express important ethical norms, it is the first principle that is primarily relevant to the food vs. fuel debate. A right to food is included in the United Nations Declaration of Universal Human Rights. As such, in stating that biofuels should not be developed at the expense of people's essential rights, the Council stipulates an ethical condition that precludes the outcomes decried by those who mount a food vs. fuel critique. However, the Council also states that the conditions articulated in the five principles do not preclude the development of biofuels. Focusing again on the first principle, a rationale for this statement can be derived from the fact that meeting global food needs is entirely feasible given current crop production capabilities. So the thrust of the Nuffield Council condition is not so much to forbid the development of biofuels as it is to mandate compensating programs to ensure that food needs are met, given the fact that an adequate supply of food is already available. Such programs, the Council adds, are needed even in the absence of efforts to develop plant-based liquid transportation fuels [37].

To sum up, the era of global food crisis in 2007 and 2008 saw the emergence of a food vs. fuel debate in which biofuels of all types lost a great deal of public support. However, even some of biofuels most severe critics have endorsed the view that the food vs. fuel critique should not be regarded as a permanent indictment against all forms of plant-based liquid transportation fuels. The food $v s$. fuel critique depends upon two elements. First there is an empirical claim linking biofuels to a rise in global food prices. Second, there is an ethical premise articulating why a rise in food prices constitutes an ethically indefensible insult to those living in extreme poverty. Most responses in the technical literature address the empirical premise. They assert that the causal link can be broken by emphasizing crops that are not utilized for food. Cellulosic biofuels would be a prime example. It is important to notice that this tactic for responding to the food $v s$. fuel critique leaves the key ethical premise standing: Emphasizing non-food crops says nothing to contradict the assumption that anything causing an increase in global food prices is a moral evil. The Nuffield Council analysis, on the other hand, implies that the key ethical premise is mistaken: If programs to meet the basic food needs for the poor are put in place, something that causes prices to rise would not be morally unacceptable. The analysis that follows can be read as an amendment to the Nuffield principles.

\subsection{Stage I: Why a Focus on Non-Food Crops Misses the Mark}


Given the technical community's emphasis on breaking the causal link between plant-based liquid fuels and food insecurity, the agricultural ethics of biofuels must begin by demonstrating why this response fails to address the criticisms of biofuel development that were mounted in the food vs. fuel debate. As noted above, the economic models of global commodity supply and demand that generate predictions of higher food prices incorporate complex linkages among distinct agricultural commodities. In some cases, linkages reflect the fact that when the price of maize goes up, people will shift consumption to wheat or rice, or animal producers will shift to feeding more soya. This substitution effect then places upward pressure on these commodities, even though they are not currently being used as a source of sugars for biofuel production. But a more fundamental substitution effect has an equally powerful impact over the long run, and that is the fact that all forms of land use are linked in a similar way. Thus shifting from utilization of maize to miscanthus or jatropha as a biofuel feedstock will certainly have an impact on whether farmers even choose to plant food crops, in the first place. Fewer acres of maize will be planted, and the economic effect on supply and demand relationships for maize will be very similar to what would have occurred if ethanol were simply produced from maize, in the first place. The fact that planting decisions have less flexibility that corn futures moderates the volatility of these land-use substitution effects, as does the fact that most climates are better adapted to production of some crops rather than others. Nonetheless, over the long run relying on the use of non-food crops as fuel feedstocks will translate into land use decisions that preserve the same food $v$. fuel tensions noted in the original critiques [38].

Furthermore, neither the utilization of crop residues not currently used for food nor the development of cellulosic ethanol resolves this ethical tension. This is so even if it is true that lands suitable for cellulosic feedstocks are entirely unsuitable for food crops. The ethical issue is not one of finding technically feasible alternatives to crops currently used for food. It is rather in the socio-economic priorities that dictate which of many technically feasible possibilities will be realized in practice. Technologies capable of transforming woody biomass into digestible feedstocks for liquid fuels are essentially converting cellulose into sugar or starch that could be digested in human stomachs. If crop residues can be used for fuel, they can also be used for food. If wood-based fuels are possible, then wood-based foods are also possible. Thus if there is an ethical tension between using maize and sugarcane for ethanol when they could be used for direct human consumption or as animal feeds, one could argue that the same ethical tension will arise in using residues or cellulosic sources for fuel: these are now potential sources of calories for human consumption. One can ask, why are these plant sources being used for fuel when they could be utilized in practices that would stabilize (or perhaps even lower) the global price of food?

Specialists who are deeply involved in the development or analysis of biofuels may find this argument surprising or even silly, but such a reaction is itself indicative of the deeper ethical point. The fact that no one is even suggesting that these cellulosic technologies be deployed as a response to world hunger is indicative of the relative value judgments embedded in the respective commodity prices of food and fuel. It would be highly impractical to utilize the tools of advanced genetic engineering and catalysis to convert woody biomass into food for human consumption, and this impracticality derives from the fact that it would be impossible to recover the cost of developing these tools if they were being conceptualized as a food technology. But perhaps this simply shows that as a society we place much higher value on fuel than we do on ensuring that poor people are adequately fed. 
We are willing to pay much more to fuel our vehicles than we are to feed the poor. Understood as a moral point this is just what the original food vs. fuel critique may have been meant to establish.

As such, a more sophisticated statement of the original food $v$. fuel critique might go like this: Yes, it is logically possible to imagine a world in which the poor's right to food is protected by grants and gifts, even in a context of increasing demand and attendant overall scarcity of food commodities. But this would require a dramatic reallocation of fiscal resources to the poor. Biofuels are thus ethically problematic because they merely reflect the (ethically) skewed priorities of current markets for agricultural commodities. The point is expressed in the following rhetorical question: Given the fact that we cannot even imagine devoting resources to expanding the food supply by giving humans the ability to consume woody biomass, why would we think that resources will be available that would enable poor food-buyers' to compete with rich drivers of SUVs in the market for existing sugars and starches? Note that this version of the argument also militates against the policy-oriented response recommended by the Nuffield Council principles. It implies that given current the social priorities reflected in agricultural prices, the Nuffield Council's suggestion that negative impacts from the economic effects of biofuels could be offset by compensating policy is naïve. The key ethical claim is to challenge the moral justification of those priorities.

This account of the food $v s$. fuel tension is admittedly more abstract than the picture painted in editorials by George Monbiot and others, and as result it may also be less persuasive. Nevertheless, it shows why a robust ability to convert all manner of plant biomass into an alternative form of energy does nothing to redress the ethical tensions between food and fuel. It only increases them. If humanity were committed to feeding the poor, (so the argument goes) no biomass that could digested by human beings would ever be burned as fuel unless everyone had already been adequately fed. The growth of markets for ethanol shows that society is not committed to feeding the poor, and that is the ethical point that editorials against biofuels are trying to make. A logically consistent version of this argument has broad implications. Not only is it ethically problematic to burn ethanol or to invest in new biofuel technology development before we commit resources to feeding the poor, it would be ethically problematic to place any consumptive activity of comparably lower moral significance above feeding the poor. This would include buying cosmetics, attending a football match or spending money that one could have given to a relief program on any non-essential good. Notably, Peter Singer has made precisely this argument in his very influential analyses of hunger as a moral problem, [41,42].

Singer's argument advocates what an economist would call "a change in tastes," a shift in the priorities that order the way that each of us as individuals allocates our resources. The argument says that we should change our priorities because the upshot of acting on our current preferences is morally indefensible. It is not implausible to interpret Monbiot's critique as a less sweeping and perhaps less radical version of the same argument: We need to change our priorities, and rejecting biofuel is a small way that we can do this. It is important to recognize that from this perspective, shifting consumption from maize or sugarcane based ethanol to biofuel from crop residue or cellulosic feedstocks is not really a change in priorities. It is more like using the money that one might have spent on a football match to attend a concert, then congratulating oneself on one's moral superiority for resisting the impulse to watch football instead of helping the poor. 


\subsection{Stage II: A Better Analysis of Hunger}

However, Singer's radical position is not the last word in an ethics of hunger. The beginnings of a more adequate reply to critics of biofuel can be derived from close examination of some key ambiguities in the ethical assumptions implicit in the food $v s$. fuel debate, and it will be useful to rehearse this argument yet again. The wealthy driver of an SUV can afford to pay more for a luxury than the poor person can pay for a necessity, it is claimed, so the idle consumption of the rich contributes to the wretchedness of the poor. If food is seen to be in conflict with biofuel because what might be eaten by a poor person is burned as fuel by a rich person, the economic implication is that both rich and poor are competing to purchase the underlying biomass for alternate purposes. This competition can then be viewed as an ethical problem because one purpose (the poor person's) has a morally compelling justification that the other lacks. The view that we can reduce the tension by trying to segregate the market for food from the market for fuel neglects the fact that there are also competitions for land use, as well as for technology development. The fact that poor people cannot compete with rich people for basic grains is structurally isomorphic to the fact that they cannot compete with the rich when it comes land use allocation or to capital investment in new technology. The poor go hungry when the rich fuel their vehicles, but they go hungry when the rich do anything other than devoting their wealth to helping the poor. The structural inequality is indeed an ethical problem, but there is really nothing here that is uniquely related to biofuel. It is a problem of the ages.

Runge and Senaur, at least, may be making an ethical argument that is subtly, but importantly different. It is not just that rich and poor engage in a competition for resources. The claim is that biofuels actively tilt this age-old competition more firmly in the direction of the rich. This makes promotion and development of biofuel into something that actively harms poor people who would not have suffered in the absence of programs to develop and deploy liquid transportation fuels derived from plant-based sources. Biofuels are then morally wrong not because food is in ethically more important good than fuel. There are and would be hungry people in a world where people engage in morally trivial forms of consumption, whether biofuels exist or not. Biofuels are wrong because developing them drives people who are not now in a state of hunger into the state of hunger. Biofuels cause harm to those specific individuals who would not have gone hungry if food prices had not risen as a result of developing them. If this is Runge and Senaur's intent, their argument is consistent with Thomas Pogge's claim that ethics of world poverty should focus on the negative duties of the affluent: the duty not to actively harm the poor. This may be viewed as an ethically more potent claim than unrealizable goals of global economic equality [24].

However, a second ambiguity arises in connection with the way that harm is specified, given the highly aggregated picture of hunger that is derived from the standard economic analysis. The concept of harm takes on moral significance when an identifiable individual is harmed. Groups do not go hungry. Groups cannot be harmed in the sense relevant to hunger except in so far as some individual members of the group are harmed. Thus, the claim that biofuels harm the poor is not a general claim about "the poor" as a group; it implies that specific poor individuals are harmed. The critique against biofuels is persuasive in part because it is easy for the readers of British or American newspapers to imagine how causing the price of food to rise causes harm to a person who can no longer afford to buy the food they need. News reports of riots among the urban poor validate the imagination in this respect. 
However, the ease with which citizens of industrialized nations conjure this image conceals important dimensions of the food insecurity that is experienced by poor people in non-industrialized countries.

As Amartya Sen has argued, hunger is caused by insecure food entitlements. A food entitlement describes the way that a given individual gets access to food. Simplifying slightly, there are three basic models for food entitlements. A production-based entitlement means that people raise or scavenge the food they eat. Their entitlement is based directly on a productive activity. An income-based entitlement arises when food is purchased on markets. It is made vulnerable by threats to the source or buying power of a person's income. Finally, some people depend on third parties to supply a grant or gift entitlement. Children are often in this situation, as are those who depend on charity and government food programs in order to eat. Sen's analysis was intended in part to rebut the assumption that hunger is simply a function of food availability. His study of the Bengal famine of 1943 showed that adequate supplies of food were locally available throughout the famine. Hunger was caused when rapid inflation dramatically reduced the buying power of poor people relying on an income based entitlement to secure their food needs, $[43,44]$.

However, the food vs. fuel critique assumes that all people get access to food by purchasing it, or through what Sen calls an income-based entitlement. The argument put forward by food vs. fuel critics also asserts that global scarcity is the primary threat to the security of income-based food entitlements: Competing uses increase scarcity, driving up prices which cannot be paid by the poor. Sen's work suggests two complementary responses to this argument. First, it is fluctuations in buying power that threaten income-based entitlements, and that such fluctuations are as likely to be associated with macro-economic phenomena (such as rapid inflation) as with shortages in the food supply. Nevertheless, the potential for supply or demand driven increases in the price of food are indeed potential threats to the security of an income-based entitlement, so an increase in the price of food does have the potential for moral significance in just the way that the food $v s$. fuel critique imagines it. It is valid to see such people as harmed by biofuels. But the more significant result of Sen's work lies in the fact that the income-based entitlement is an accurate analysis of hunger for a minority of the global population living in extreme poverty. Considering the way that biofuels affect other forms of food entitlement dramatically complicates the claim that biofuels harm the poor.

Grant-based entitlements apply to people who depend on gifts of food, either from other individuals, from charitable organizations or from governments. Their food entitlements can become insecure either because grantors ability to deliver food is itself threatened, or because grantors' commitment fades. Either of these circumstances might be affected by a rise in global food prices, though to the extent that a rise in global food prices causes an increase in the awareness of hunger, commitment to grants and gifts might increase, rather than declining. As such, the relationship between an increase in food prices and grant-based entitlements is complex. It is, however, the production-based entitlement that is of most relevance to the agricultural ethics of biofuels. A production-based entitlement means that a person produces their own food, either through plant and animal agriculture or through some form of scavenging. The traditional threats to production-based entitlements have been natural disasters: storm, drought, or an insect plague, on the one hand, or deliberate human actions such as vandalism, theft and war. The category of theft should be understood to include a variety of ethically illegitimate forms of taking, including the appropriation of a producer's control over the means of production, especially land. That is, a production-based entitlement is insecure to the extent that a 
person's ability to control the land on which their production depends is threatened. Developments that weaken land tenure for the poor threaten their food entitlement. As will be discussed below, biofuels could be associated with land acquisition efforts that abrogate tenure, and to the extent that they do so, they provide a clear threat to production-based food entitlements. Guarding against such incursions on land tenure was a primary thrust of the Nuffield Report.

For the moment, however, the focus is on how production-based entitlements are affected through the mechanisms of legitimate market transactions. First and foremost, it is important to recognize that market forces are not entirely absent from the security of production-based entitlements. Virtually all farmers depend on selling some portion of their production in order to meet basic needs. One of the main threats to the security of a production-based entitlement is thus a decline in the return they receive on the sale of their agricultural commodities in comparison to what they must pay for those goods that must be purchased. These relationships are quite varied. Some producers simply sell a portion of a crop that they will save and eat themselves, but many will plant both subsistence and cash crops with the intent of selling the latter. Furthermore, production-based food entitlement seldom implies that one is exclusively a seller, rather than a buyer of food. Diets are supplemented with purchased food, especially as stored supplies from prior crops are exhausted. Poor farmers who derive income from non-food crops such as cotton, tobacco, coffee or tea may purchase a relatively large share of the food they eat, though few depend exclusively on purchased food [45]. Given this variety, one must be cautious about inferring how a given biofuel crop would affect any given production-based food entitlement, but the net effect can be stated simply: Other things equal, an increase in the relative price of agricultural commodities tends to strengthen a production-based entitlement. Thus, if biofuels cause a general uptick in the price for agricultural commodities, this should, in theory, benefit poor people who have a production-based entitlement.

This theoretical linkage extends to poor people who work in agriculture without owning or controlling their land, though in their case it is significantly weaker. Landless laborers may derive compensation in the form of a "share" of the crop, or they may have permission to cultivate a portion of land for their own use. In these cases, their food entitlement is also at least partially production-based. But in other cases, they may simply receive a daily wage, in which case their food entitlement is almost entirely income-based. To the extent that the market for agricultural labor is a function of agricultural prices, there can be a positive relationship between the strength of their food entitlement and the price of food, but this will not be significant in areas where there is a surplus of labor available for hire in the fields and plantations. In the case of both agricultural laborers and poor farmers who have secure tenure, however, it is important to recognize that an ethics of hunger based solely on assumptions about the adverse effects of rising food prices is not providing an adequate picture.

To summarize, the food vs. fuel critique advanced in the Western press provides a reasonable analysis of what is ethically significant about the food-related effects of biofuels for those who live in cities and depend solely on purchases for accessing their food. The analysis of United Nations Rapporteur on Food Olivier de Schutter suggests that about $20 \%$ of those currently falling below the World Bank standard for extreme poverty (less than $1 €$ per day of income) fall into this category. However, for those whose food-entitlement is related to agricultural production, the effect of rising food prices can be positive. De Schutter estimates that about $50 \%$ of those in extreme poverty are 
agricultural producers, while another $20 \%$ are landless laborers. The remaining $10 \%$ are scavengers who derive a living from accessing common pool resources available in forests are fisheries. As such, they too depend at least partially on a production-based food entitlement [46]. Thus the presumption that rising food prices are unilaterally disastrous to the world's poorest people is based on a faulty understanding of the ethics of hunger.

\subsection{Stage III: Implications for Biofuels}

Sen's analysis of food entitlements is important for the agricultural ethics of biofuels because it shows why the original food $v s$. fuel debate missed ethically important dimensions of global hunger. It also indicates why responses to that debate must acknowledge both the impact of prices on the income-based entitlements of the urban poor and the complex role that competing land-use applications play in strengthening or weakening the production-based food entitlement of the rural poor. In this respect, the entitlement analysis of hunger shows why the current conceptualization of the trilemma fails to fully address the ethical issues created by a food $v s$. fuel tension. Biofuels could be beneficial to poor farmers in developing country settings. It would, however, be fallacious to presume that this theoretical possibility resolves the ethical problems identified by those who launched the original food $v s$. fuel debate. There are at least two reasons. One is derived from ethical theory, while the other is derived from empirical studies of agricultural development and its impact on the poor.

The empirical argument for concluding that the theoretical potential of benefit to the rural poor fails to satisfy the requirements of ethics is that such theoretical benefits are frequently unrealized in reality. People in extreme poverty are also people whose overall vulnerability means that they are often in no position to prevent unjust exploitation, even when their interests are protected by law and property codes. The increase in the value of their land or their commodity crops that is theoretically created by a rise in commodity prices is appropriated by other actors in the food system, including grain traders, shippers, wholesalers, and retailers, rather than accruing to the farm operator. If the increased value of agricultural production is associated with a new technology (and it is clear that this would be the case with respect to biofuels) the value is appropriated by the developer of the technology, instead of the poor producer. For reasons such as this, there is a now a broad skepticism about the ability of innovations in agricultural technology to actual benefit the poor. This skepticisms is widely in evidence in writings on biofuels $[47,48]$.

Whether a change in production methods involves the cultivation of a new crop or cultivar, the utilization of new management techniques or the purchase of inputs such as machinery, chemicals or seeds, there is a robust tendency for first movers to derive the lion's share of benefit. Late adopters often find themselves in hopelessly uncompetitive circumstances by the time that the effect of technological innovation is "priced in" to reflect efficiencies or other changes in commodity markets [49]. It is only when extensive efforts to insure that poor farmers have both access to high quality disinterested information on new technologies, and opportunities to limit the inherent risks of experimenting with unproven techniques that the inegalitarian tendencies of technological innovation in agriculture can be tempered. What is more, production systems that favor plantation style management of large labor forces or that require major capital investment simply cannot be adopted by farm producers at the lower end of the economic scale. 
As noted above, there is already some evidence that rising agricultural commodity prices are increasing land values, and that the effect of this has been a rash of land acquisitions that have dispossessed poor farmers of their tenure. Here, the broad sociological critique of technological innovation translates into a weakening of the land rights on which production-based food entitlements depend. There are numerous reports of land speculation based on the expectation that biofuels will dramatically alter the economics of land use over the next two decades. This can have disastrous effects on poor farmers, especially when speculators exploit political corruption or where there is inherent uncertainty in the status of property titles and land rights. More basic and enduring troubles for the poor reside in the way that shifts in agricultural technology have historically tended to produce negative effects on farmers that are felt disproportionately by those who are less well educated, less well capitalized and less able to experiment with new alternatives, in short, the poor, [50,51].

The ethical argument builds on Sen's and de Schutter's analyses, which shows that that the food vs. fuel critique applies straightforwardly to only $20 \%$ of those living in extreme poverty, and that perhaps as many as $80 \%$ could benefit. But this is only a broad diagnosis of the ethical problem; it is in no way a resolution of it. Some interpretations of utilitarian ethics would imply that if the value of benefits exceeds the value of harm, an action or policy can be ethically justified. But many advocates of this principle would qualify its application by insisting on an additional criterion motivated by distributive justice: the principle should not be applied when benefits are gained at the expense of the poor. In the case outlined above, both winners and losers suffer from extreme poverty. It is therefore not implausible to suggest that if the benefits of biofuels to the poor do outweigh the costs to the poor, the development of plant-based liquid transportation fuels is ethically justified: Development of biofuels is justified because the benefit accruing to the more numerous rural poor offsets harm from any increase in the price of food that falls upon the urban poor. However, this finding would be challenged by an alternative tradition in ethical theory. A Kantian might claim that in this case, the urban poor are being treated as a means for advancing the interests of the rural poor. Consciously rationalizing harm to one person in order to benefit another is, on this view, an affront to the dignity of the person harmed. For someone persuaded by Kantian ethics, this result is enough to hold that developing biofuels under such a rationale is inherently unethical.

There is, however, a response to this concern for human dignity. It is important to recognize that the entitlement analysis of hunger also implies that not developing biofuels is unethical under a Kantian interpretation. The strategy of holding food prices low benefits the urban poor at the expense of the rural poor, so on this horn of the dilemma, the rural poor are being treated as a means for advancing the interests of the urban poor. The result is thus a conundrum. The only way out is to find actions to change the empirical circumstances that put the interests of the urban and rural poor at cross purposes. Thus the real significance of the Kantian argument is to create an ethical obligation to search for ways in which this tension can be mitigated. Two broadly stated strategies suggest themselves: (1) find ways to develop and implement biofuels that return the sought for benefits to the rural poor without affecting the global price of food commodities; (2) find ways to offset the impact of a price-rise on the food entitlements of the urban poor either through grant and gift entitlements or through other strategies that allow their income to keep up with the rising cost of food.

It is beyond the scope of this paper to delve further into the way that either of these strategies might be pursued. It is clear that some defenders of biofuel believe themselves to be pursuing the first 
strategy, though the analysis given above was intended to show why this is more difficult than is commonly imagined. In the absence of some general shift in social priorities, it is difficult to defend business-as-usual development of biofuels without an accompanying commitment to programs that would strengthen the capabilities of poor people. While the use of non-food crops or crop residues might be implemented in a manner that does this, simply shifting to non-food crops grown by comparatively well-off developed country farmers could have very uncertain impacts on poor farmers. The volatility introduced into agricultural commodity prices by linking them to the price of oil would be a prominent case in point.

The concluding point is that an agricultural ethics of biofuels does entail a positive obligation for those in the science and business communities: They must acknowledge the conflict between urban and rural interests and commit themselves to resolving it, if only through exhortation and consciousness-raising. In the absence of both government policy and private sector efforts to the contrary, the most likely impact of biofuels would be that small scale producers are either frozen out of any opportunity to grow biofuel crops, and that those who do will suffer irreparable economic reverses when faced with competition from better capitalized farmers. They will be left to produce lower value crops, or will be bankrupted during the early days of transition to a bioeconomy. It is for this reason that many social scientists writing on biofuels predict disastrous impact on poor or small-scale producers in the developing world. As positive scientists, these social analysts are generally loathe to incorporate moral judgments into their studies. In shifting from social science to ethics, it is therefore notable that the empirical critique of development actually results in the same conclusion as a critique based on ethical theory. An ethics of biofuels might hold the scientists, investors and policymakers who orchestrate such a transition to biofuel collectively responsible for economic and personal losses, the suicides, the dislocation and the attendant hunger and death from this transition, at least in so far as this community of biofuels developers fail to make any response to the moral complexities their technologies provoke. Scientists, business and possibly also politicians acquire ethical responsibilities to find ways for mitigating the tension between the interests of urban and rural poor. The empirical critique shows how difficult this will be, but it provides nothing that dissipates the obligation to try. It is not that we should hold innovators morally responsible for harms that occur in spite of their best efforts, but those who proceed blithely ahead as if someone else will address these issues deserve condemnation.

\section{Conclusions}

Biofuels could be a positive force in addressing the circumstances that cause hunger among the roughly $80 \%$ of the world's poorest people whose food entitlement is tied closely to agricultural production. The reason for this is that these poor farmers do indeed need to improve both the biological effectiveness of their farming methods as well as the economic return on their farming labor [45]. Next generation biofuel technologies could theoretically be developed with cognizance of the farming systems being currently deployed by these poor producers. If they were, they could be one strategy for addressing the first half of what these poor producers need. The effect of biofuel on global agricultural commodity prices that is the substantive basis of the food $v s$. fuel critique would then have a beneficial impact on poor producers' economic return. The result would be that their largely 
production-based food entitlements would be more secure in a world with appropriate biofuel technology than they are today.

This would not resolve the food vs. fuel tension for the $20 \%$ who do depend on very limited incomes that are not derived from agricultural production. Since many of these poor live in urban areas, they are a very visible and potentially noisy segment of the poor. However, an ethics of hunger would suggest that their needs should not be met at the expense of strengthening production-based entitlements among agricultural producers and laborers. Hence to think that one has said all that needs to be said about an ethics of food $v s$. fuel by coming out in favor of low food prices is to favor the needs of one group of poor people at the expense of others. An adequate ethics of hunger will need to address income-based entitlements in a way that does not simultaneously weaken production-based entitlements. The "food $v s$. fuel" critique is thus valid for a minority of the world's poor.

An ethics of hunger must recognize that as plausible as the food $v s$. fuel story may sound to those of us who shop at grocery stores or purchase meals at restaurants, this income-based way of understanding the causes of hunger distorts the way that a right to food would actually be implemented for the majority of people living below the current standard for extreme poverty. For perhaps $80 \%$ of the world's population, hunger is tied to the production of agricultural commodities in subtle and complex ways. This means first that increases in the price of agricultural commodities are not always morally problematic, but more importantly it means that agricultural technologies - and plant-based liquid transportation fuels are either directly or indirectly agricultural technologies - deserve careful design and implementation in order to avoid devastating impacts on poor people. Given this, there are many reasons to express skepticism about the current trajectory of biofuels. Although defenders of biofuels argue that they can benefit poor farmers, there is very little discussion of the peculiar vulnerabilities that poor farmers face in an era of rapid technological change. As such there is every reason to suspect that many of the scientists, public institutions and private firms that are in the process of developing the next generation of biofuels operate from a position of naiveté about the most likely impact of the technology that they are developing.

The upshot of a more satisfactory "food vs. fuel" ethic for biofuels is to recognize that implementation of biofuels can strengthen food entitlements for poor farmers and farm labor, but that it is unlikely to be beneficial in the absence of extensive ongoing efforts to insure that the mix of production technologies is extended to them in a manner that is consistent with their ability to use them under existing conditions. This means that the overarching guidelines that the Nuffield Council developed in connection with existing ethanol and biodiesel transportation fuels are also relevant to cellulosic technologies that are still in development. Much of this work will involve questions that extend far beyond this paper's focus on the food $v s$. fuel debate. Indeed, the larger lesson of the food $v s$. fuel debate may be to reinforce the ethical significance of a comprehensive and conscientious effort to understand and respond to the complexities of technological innovation and the processes of human and economic development.

\section{References and Note}

1. Thompson, P.B. The agricultural ethics of biofuels: Climate ethics and mitigation arguments. Poiesis Praxis Int. J. Technol. Assess. Ethics Sci. 2012, 8, 169-189. 
2. Thompson, P.B. The agricultural ethics of biofuels: A first look. J. Agric. Environ. Ethics 2008, 21, 183-198.

3. Belden Russanello and Stewart. Public Opinion on Federal Farm and Biofuels Policy: Highlights from the 2010 Survey on Agriculture and the Environment; Technical Report, 2011. Available online: http://www.farmsfoodandfuel.org/system/files/BRS\%202010\%20Poll\%20Highlights_2.pdf (accessed on 6 July 2012).

4. Monbiot, G. Feeding Cars, Not People. Manchester Guardian, 23 November 2004. Available online: http://www.monbiot.com/2004/11/23/feeding-cars-not-people/ (accessed on 6 July 2012).

5. Monbiot, G. If We Want to Save the Planet, We Need a Five-Year Moratorium on Biofuels. Manchester Guardian, 26 March 2007. Available online: http:/www.guardian.co.uk/ commentisfree/2007/mar/27/comment.food (accessed on 6 July 2012).

6. Monbiot, G. An Agricultural Crime against Humanity. Manchester Guardian, 6 November 2007. Available online: http://www.monbiot.com/2007/11/06/an-agricultural-crime-against-humanity/ (accessed on 6 July 2012).

7. Brown, L.R. Starving for fuel: How Ethanol Production Contributes to Global Hunger. The Globalist, 7 August 2006. Available online: http:/www.theglobalist.com/StoryId.aspx?StoryId $=5518$ (accessed on 11 February 2012).

8. Ayre, M. Will Biofuel Leave the Poor Hungry? BBC News, 3 October 2007. Available online: http://news.bbc.co.uk/2/hi/business/7026105.stm (accessed on 6 July 2012).

9. Milmo, C. Biofuel: The Burning Question. The Independent, 15 April 2008. Available online: $\mathrm{http}: / / \mathrm{www}$. independent.co.uk/environment/climate-change/biofuel-the-burning-question-08959.html (accessed on 6 July 2012).

10. Tennenbaum, D.J. Food vs. fuel: Diversion of crops could cause more hunger. Environ. Health Perspect. 2008, 116, A254-A257.

11. Runge, C.F.; Senauer, B. How biofuels could starve the poor. Foreign Aff. 2007, 86, 41.

12. Runge, C.F.; Senauer, B. How Ethanol Fuels the Food Crisis. Foreign Affairs, 28 May 2008. Available online: http://www.foreignaffairs.com/articles/64915/c-ford-runge-and-benjaminSenaur/how-ethanol-fuels-the-food-crisis (accessed on 26 October 2012).

13. Barrionuevo, A. Rise in Ethanol Raises Concerns about Corn as a Food. The New York Times, 5 January 2007. Available online: http://www.nytimes.com/2007/01/05/business/05ethanol.html (accessed on 6 July 2012).

14. Bradsher, K. A New, Global Oil Quandary: Costly Fuel Means Costly Calories. The New York Times, 8 January 2008. Available online: http://www.nytimes.com/2008/01/19/business/ worldbusiness/19palmoil.html?_r=3\&pagewanted=all (accessed on 6 July 2012).

15. Holt-Giménez, E. The Biofuel Myths. The New York Times, 7 July 2007. Available online: http://www.nytimes.com/2007/07/10/opinion/10iht-edholt.1.6588231.html?pagewanted= all (accessed on 10 July 2012).

16. Rosenthal, E. The Pump vs. Dinner-Getting Biofuel Subsidies Right. The New York Times, 29 May 2007. Available online: http:/green.blogs.nytimes.com/2007/05/29/the-pump-vs-dinnergetting-biofuel-subsidies-right/ (accessed on 6 July 2012). 
17. Runge, C.F.; Senauer, B. How biofuels could starve the poor. The New York Times, 7 May 2007. Available online: http://www.nytimes.com/cfr/world/20070501faessay_v86n3_runge_Senaur. html?pagewanted=all (accessed on 6 July 2012).

18. Brown, L.R. Who Will Feed China? Wake-Up Call for a Small Planet; W. W. Norton \& Company: New York, NY, USA, 1995.

19. Cassman, K.G.; Liska, A.J. Food and fuel for all: Realistic or foolish? Biofuels Bioprod. Biorefin. 2007, 1, 18-23.

20. Rosegrant, M.W.; Zhu, T.; Msangi, S.; Sulser, T. Global scenarios for biofuels: Impacts and implications. Appl. Econ. Perspect. Policy 2008, 30, 495-505.

21. Tyner, W.E.; Taheripour, F. Policy options for integrated energy and agricultural markets. Rev. Agric. Econ. 2008, 30, 387-396.

22. Shue, H. Basic Rights: Subsistence, Affluence and U.S. Foreign Policy; Princeton University Press: Princeton, NJ, USA, 1980.

23. O’Neill, O. Faces of Hunger: An Essay on Poverty, Justice and Development; G. Allen \& Unwin: London, UK, 1986.

24. Pogge, T. World Poverty and Human Rights: Cosmopolitan Responsibilities and Reforms; Polity Press: Cambridge, UK, 2002.

25. De Gorter, H.; Just, D. Why Sustainability Standards for Biofuel Production Make Little Economic Sense. Policy Analysis, 7 October 2009. Available online: http://li25-248.members. linode.com/files/pa647.pdf (accessed on 6 July 2012).

26. Hill, J.; Nelson, E.; Tilman, D.; Polasky, S.; Tiffany, D. Environmental, economic, and energetic costs and benefits of biodiesel and ethanol biofuels. Proc. Nat. Acad. Sci. USA 2006, 103, 11206-11210.

27. Fargione, J.; Hill, J.; Tilman, D.; Polasky, S.; Hawthorne, P. Land clearing and the biofuel carbon debt. Science 2008, 319, 1235-1238.

28. Searchinger, T.; Heimlich, R.; Houghton, R.A.; Dong, F.; Elobeid, A.; Fabiosa, J.; Tokgoz, S.; Hayes, D.; Yu, T.-H. Use of U.S. croplands for biofuels increases greenhouse gases through emissions from land-use change. Science 2008, 319, 1238-1240.

29. Solomon, B.D.; Barnes, J.R.; Halverson, K.E. Grain and cellulosic ethanol: History, economics and energy policy. Biomass Bioenergy 2007, 31, 416-425.

30. Wikipedia. Food vs. Fuel, 2012. Available online: http://en.wikipedia.org/wiki/Food_vs._fuel (accessed on 10 July 2012).

31. Lane, J. Perception vs. Reality: The 8 Most Common Biofuels Myths. Biofuels Digest, 8 June 2012. Available online: http://www.biofuelsdigest.com/bdigest/2012/06/08/perception-vs-realitythe-8-most-common-biofuels-myths/ (accessed on 12 July 2012).

32. Carey, J.; Carter, A. Food vs. Fuel. Business Week Magazine, February 2007. Available online: http://www.businessweek.com/stories/2007-02-04/food-vs-dot-fuel (accessed on 10 July 2012).

33. Mortimer, N. Ethics for Biofuels and Everything Else. Significance, September 2011, pp. 108-111.

34. Tilman, D.; Socolow, R.; Foley, J.A.; Hill, J.; Larson, E.; Lynd, L.; Pacala, S.; Reilly, J.; Searchinger, T.; Somerville, C.; et al. Beneficial biofuels-The food, energy, and environment trilemma. Science 2009, 325, 270-271. 
35. The Post-Alcohol World. The Economist, 28 October 2010. Available online: http:/www. economist.com/node/17358802?story_id=17358802 (accessed on 10 July 2012).

36. Tait, J. The ethics of biofuels. GCB Bioenergy 2011, 3, 271-275.

37. Nuffield Council on Bioethics. Biofuels: Ethical Issues; Technical Report; 2011.

38. Gamborg, C.; Millar, K.; Shortall, O.; Sandøe, P. Bioenergy and land use: Framing the ethical debate. J. Agric. Environ. Ethics 2012, doi:10.1007/s10806-011-9351-1.

39. Macer, D. Ethics and biofuels. Biofuels 2011, 2, 247-249.

40. Buyx, A.; Tait, J. Ethical framework for biofuels. Science 2011, 332, 540-541.

41. Singer, P. Famine, affluence and morality. Philos. Public Aff. 1972, 1, 229-243.

42. Singer, P. The Life You Can Save: Acting Now to End World Poverty; Random House: New York, NY, USA, 2009.

43. Sen, A.K. Poverty and Famines: An Essay on Entitlement and Deprivation; Oxford University Press: Oxford, UK, 1983.

44. Drèze, J.; Sen, A.K. Hunger and Public Action; Oxford University Press: Oxford, UK, 1991.

45. Mazoyer, M.; Roudart, L. A History of World Agriculture from the Neolithic Age to the Current Crisis; Earthscan Books: London, UK, 2004.

46. De Schutter, O. Address to the One Just World Forum, Melbourne, Australia, 20 June 2012.

47. McMichael, P. The agro-fuels project at large. Crit. Sociol. 2009, 5, 825-839.

48. White, B.; Dasgupta, A. Agrofuels capitalism: A view from political economy. J. Peasant Stud. 2010, 37, 593-607.

49. Cochrane, W.W. The Development of American Agriculture: A Historical Analysis, 2nd ed.; University of Minnesota Press: Minneapolis, MN, USA, 1993.

50. Daniel, S. Land Grabbing and Potential Implications for World Food Security. In Sustainable Agricultural Development; Behnassi, M., Shaheed, S., D’Silva, J., Eds.; Springer: Dordrecht, The Netherlands, 2011; Volume 1, pp. 25-42.

51. Hyer Toft, K. "Land Grab", Human Rights and Ethical Concerns about Biofuels. Presented at Conferences of Faculty of Science Radboud University, Old World and New World Perspectives on Environmental Philosophy, Nijmegen, The Netherlands, 14 June 2011.

(C) 2012 by the authors; licensee MDPI, Basel, Switzerland. This article is an open access article distributed under the terms and conditions of the Creative Commons Attribution license (http://creativecommons.org/licenses/by/3.0/). 